\title{
A comparison of the nursing competence of graduates and diplomates from UK nursing programmes
}

\author{
INFORMATION POINTS: \\ Analysis of variance \\ (ANOVA) \\ Wilks' lambda
}

HELEN P. BARTLETT BA, MSc, PhD, RGN, RHV

Director, Oxford Centre for Health Care Research E Development; Deputy Head (Research), School of Health Care

VANESSA SIMONITE BSc, MSc

Senior Lecturer, School of Computing E Mathematical Sciences

ELIZABETH WESTCOTT RGN, MSc

Senior Lecturer, School of Health Care

HEIDI R. TAYLOR BA, MA

Research Assistant, Oxford Centre for Health Care Research E Development

Accepted for publication 5 April 1999

\section{Summary}

- This paper reviews the literature on nursing competence measurement and reports the results of a comparative quantitative study of the competencies of Project 2000 diplomates and BA (Hons) Adult Nursing graduates from two UK nursing programmes.

- The findings reveal that graduates appear to overcome any initial limitations and become more competent than the diplomates in certain areas.

- Attention to social awareness and participation is necessary in both preregistration programmes, whilst greater attention could be given to graduates' leadership and management development.

- Diplomates need support in their professional development if they are to achieve the same level of competence as graduates during the first post-qualifying year.

- There are implications for the level of support afforded to qualifying nurses in their first staff positions; preceptorship programmes could be an important means of assisting newly qualified staff to gain confidence. More research on nurse competencies with larger samples drawn from programmes across the UK is needed.

Keymords: degree programmes, diploma programmes, nurse competence, pre-registration nurse education, Project 2000.

Correspondence to: Professor Helen Bartlett, Oxford Centre for Health

Care Research and Development, Oxford Brookes University, 44 London

Road, Headington, Oxford, OX3 7PD (Tel.: 01865 485275). 


\section{Introduction}

This study aimed to compare the outcomes of two different pre-registration nurse education programmes by examining the career aspirations, competencies and role orientation of BA (Hons) Adult Nursing graduates and Project 2000 diplomates. This paper focuses on the findings related to nurse competencies. Using a structured instrument, graduates' and diplomates' perceptions of their competencies were measured and then compared at three time points: on graduation, and 6 and 12 months post-qualification. The graduates' and diplomates' supervisors and mentors also completed a questionnaire on their perceptions of their students' competencies. The graduates' and diplomates' perceptions of their competencies were then compared with the perceptions of their supervisors/mentors upon qualifying.

\section{Background}

A number of research and discussion papers have explored the issue of competence testing in nursing and other professions and in particular the concept of nursing competencies. While the literature from both sides of the Atlantic reflects degree level education in a positive light, limitations have been identified in the methodology, as have a number of sources of confusion and contradiction.

\section{DEFINITIONS OF COMPETENCE}

Terminology appears to be a major obstacle to the understanding of competence assessment in nursing. As the definition of competence varies in both content and depth between papers, the generalization of findings is limited. The Concise Oxford English Dictionary (1992) defines 'competent' as being adequately qualified, capable or effective, while competence is the state of being competent. There has been no shortage of attempts to define the concept of competence, indeed it is overdefinition that has led to much confusion and contradiction (Girot, 1993a). Definitions of competence appear to be divided between those who view it as a behavioural objective and those who regard it as an interaction between emotional and technical abilities (While, 1994).

Chappel \& Hagar (1994), who identify the attributes of competence as including knowledge, emotions and values, highlight the contribution of individual characteristics to the development of competence. Girot (1993a) describes the attributes of competence as including trust, caring, communication skills, knowledge and adaptability. A broader view is taken by De Back \& Mentkowski
(1986), who state that competence is a broad, generic ability, characteristic of the person, that transfers across settings and situations and is not a set of discrete skills.' (p.276). They add that competence is developmental and also holistic and that it is made up of several integrated components including self perception, skills, affect, motivation and knowledge, and that these are all outcomes of educational processes.

\section{MEASURING COMPETENCE}

In addition, there is a failure to agree on methods which can adequately measure competence. Quantitative measures have been criticised as reductionist or task orientated and qualitative measures accused of lacking both definition and transferability between institutions. Some of the limitations of rating competence have been highlighted by Benner (1982), who argues that where competence assessment stresses the functional characteristics of a job, any ability to differentiate between the nurse with functional skills and one with deeper personal perceptions is lost. Bircumshaw (1989a) suggests that such fundamental aspects of competence as caring, interpersonal interaction and decision making are concepts which cannot easily be measured quantitatively and recommends greater use of qualitative approaches. However, Chappel \& Hagar (1994) who support the use of measurable competence standards, advocate the development of an integrated approach, incorporating the measurement of performance, emotions, values and knowledge in context.

Research in the UK has increased in complexity as the number and range of training courses has increased. The emergence of degrees and latterly Project 2000 training has led to research on differences in the competence and performance of nurses. UK studies have adopted a more qualitative approach to the assessment of competence, in contrast to the US reliance on quantitative measures, which have been criticised for being reductionist (Benner, 1982, 1984). This may explain the focus away from rating scales and tests, towards phenomenology, as advocated by Girot (1993b), and multiple assessments such as those employed by While et al. (1995a,b).

\section{RATING SCALES}

Rating scales, usually involving completion of questionnaires by an assessor and/or the assessed, have been used extensively, particularly in the USA (Hover, 1975; Howell, 1978; Schwirian, 1978; McCloskey, 1983). The method has included rating by students, their supervisors, head nurses and directors of nursing. A detailed rating 
scale was developed by Doris Slater (Wandelt \& Stewart, 1975). The Slater Nursing Competencies Scale consists of 84 items and measures the competencies demonstrated by a nurse when performing nursing actions in providing care for patients. The scale was designed to be used in retrospect or for on-the-spot assessments.

The Six-Dimension Scale of Nursing Performance developed by Schwirian (1978) is one of the few scales which has been extensively tested for validity and reliability. The questionnaire was developed as a 52 -item instrument within six general constructs following a factor analysis of nurses' self-appraisal responses and supervisors' responses to the pilot. The scales completed by supervisors showed significant differences between those students who were deemed most promising and less promising by their nurse administrators or teachers, an example of external validity. All six subscales of the revised instrument for both nurse and supervisor scores produced high internal reliability, indicated by a Cronbach alpha of .844 or above. The scale was used for appraisal, self-appraisal and assessment of educational preparation. McCloskey (1983), McCloskey \& McCain (1988), Battersby \& Hemmings (1991) and Bartlett et al. (1993) are among those who have developed instruments based on Schwirian's 6-D rating scale.

\section{OTHER MEASUREMENT APPROACHES}

Alternatives to the rating scale approach have included tests such as problem solving and the Objective Structures Clinical Examination (OSCE) (Ross et al., 1988; Gray et al. (1977) involving a paper and pencil test to measure performance in the areas of: technical skills; teaching; leadership; giving support to family and patient; interviewing for assessment purposes; actions in structured situations; and actions following observation. Observational methods have been used infrequently, although Waters et al. (1972) include an observational component in their research. Later, however, While et al. (1995a) conclude that no suitable observational measure has yet been developed that is appropriate for use in the UK.

\section{RESEARCH FINDINGS ON PRE-REGISTRATION:}

\section{EDUCATION OUTCOMES AND PERFORMANCE}

The literature suggests that nurse graduates may or may not be different from non-graduate nurses depending on which variables are being measured. This has been found both in comparisons of competence, performance and the correlation of these with the length and type of education. Some of the American literature reveals that nurses with baccalaureate degrees demonstrate more nursing competencies than associate or diploma prepared nurses (De Back \& Mentkowski, 1986). Waters et al. (1972) and McMillan (1985) also identified differences in the graduates from different educational programmes. In the domain of self and supervisor ratings, a significant, albeit not high, correlation was found in studies by McCloskey (1983), Nelson (1978) and Schwirian (1978). Howell's (1978) finding that local need and financial considerations guide the employability of graduates more than desire for more competent practitioners, highlights other variables affecting nurses from different educational backgrounds. This result reveals a potential confusion between the American research and that conducted in the UK. In the USA nurses are expected to be different, whereas in the UK they are expected to be the same, or at least do the same job, although they are not necessarily expected to emerge from courses with the same skills (Davis \& Burnard, 1992).

Further evidence to support the view that baccalaureate graduates are more knowledgeable, adaptable and respond cognitively rather than mechanically has emerged in more recent work which has explored competence in the context of the type of course undertaken. The finding that baccalaureate nurses perform more competencies because their course promotes a wider range of competencies attributes the difference to the programme rather than the individual's personal qualities. However, the research into academic levels and their relationship to competence is contradictory and further research is required.

In the UK a great deal of the work appears to have been channelled into looking at graduates' contribution to the profession. This has taken the form of follow-up studies, the majority of which were conducted in the 1980s (Fitzpatrick et al., 1993). However, there have been few attempts as yet to examine the competence or role orientation of graduates in the UK. The majority of comparative UK studies present a largely favourable view of the graduate's progress in British nursing (Bircumshaw, 1989b; While et al., 1995a,b). Bircumshaw (1989b) evaluated the perceptions of graduates held by senior nurses and, while only using a small sample $(n=11)$, found that some graduate nurses were perceived as less confident than non-graduates on qualifying. However, it was acknowledged that graduates bring a variety of skills and knowledge to a clinical area and if these are not fully recognized then graduates will not reach their full potential.

Research from Hong Kong also lends credence to the view that graduate nurses compare favourably with groups trained in other programmes, particularly in cognitive 
skills and leadership (Bartlett et al., 1993). The amount of research in the UK is likely to increase as the debate continues over the relative merits of diploma vs. degree level education, especially as many universities are now transforming their nursing degree courses into three year programmes. Future research may also be directed at establishing differences between those with different types of degree.

\section{Design}

This longitudinal descriptive study involved the administration of nurse self-completion instruments to BA (Hons) Adult Nursing graduates and adult branch P2000 diplomates on qualifying and their mentors/supervisors. The study was conducted over 1 year, with data collection points on graduation, and at 6 months and 12 months postgraduation.

\section{Settings}

The study was conducted in two university settings. The graduate nurse sample was selected from the BA (Hons) Adult Nursing Programme at the School of Health Care, Oxford Brookes University, and a comparison group of adult branch P2000 diplomates was selected from an equivalent British university. The graduate and diplomate cohorts selected began their courses in 1992 and 1993, respectively, both completing in 1996. The degree programme was of four years duration, whereas the diploma programme was completed in three years.

\section{Sample}

In 1996, all 81 students from the BA (Hons) Adult Nursing degree course at Oxford Brookes University were invited to participate in the study and 52 gave consent. From a cohort of 41 adult branch diplomates from another university, 28 agreed to participate. Of the degree students $90 \%$ were female, while $96 \%$ of the diploma students were female.

\section{Data collection and ethical considerations}

Graduates and diplomates were informed of the study by a member of the project team at the end of a scheduled class time. Information sheets and consent forms were distributed to the target group and it was stressed that participation would be voluntary. Arrangements were made to collect the completed consent forms through internal and external mail. The first set of questionnaires were distributed by designated staff and either completed on the premises or returned in a pre-paid envelope. A covering letter was attached to each questionnaire outlining the study and the participants' rights, and assuring anonymity. With the consent of the graduates and diplomates, a questionnaire and information letter was also sent to their supervisors/mentors. At 6 months and 12 months postgraduation, participants were sent a repeat questionnaire by mail.

\section{Competence instrument}

Of the various approaches to measuring competence, two were selected from the literature to inform tool development for this study. The first was the developmental approach to measurement of performance (De Back \& Mentkowski, 1986). This defines professional competence as a series of cumulative levels of complex processes involving knowledge, skills, affect, motivation and selfperception. Competencies are outcomes of the educational process. Effective nursing performance is assessed by the ratings of graduates and their managers in relation to nine behaviours: conceptualization, emotional stamina, ego strength, positive expectations, independence, reflective thinking, helping, influencing and coaching. This approach to measuring competence is particularly suitable when the curriculum objectives clearly relate to intended outcome competencies.

The second approach defines competencies in behavioural terms. It is found in the work of Schwirian (1978) who used a Six-Dimension Scale of Nursing Performance consisting of 52 items grouped into six subscales: leadership, critical care, teaching/collaboration, planning/evaluation, interpersonal relations/communications and professional development. This instrument is designed to tap observable nurse behaviours applicable to recent graduates and experienced nurses by self and head nurse ratings. This approach to measuring competence is suited to the evaluation of graduate outcomes when the curriculum objectives focus on integration of theory and practice.

The competence instrument used in this study was based on a combination of the two measures discussed above, thus enhancing the construct validity of the tool. The final tool was adapted from a Hong Kong study of graduate nurse performance (Bartlett et al., 1993). The instrument comprised 78 items, organized in eight constructs (Table 1). Competence was rated by asking subjects to state how frequently they performed each of the competencies listed. Responses were recorded using a 4-point scale, where $1=$ never, $2=$ occasionally, $3=$ usually and $4=$ always. 
Table 1 Constructs used in the measurement of competence

\begin{tabular}{ll}
\hline Construct & Description \\
\hline $\begin{array}{l}\text { Leadership } \\
\text { Professional development }\end{array}$ & $\begin{array}{l}\text { ability to lead and make decisions (12 items) } \\
\text { participation in continuing education and upgrading of professional } \\
\text { standards (9 items) } \\
\text { ability to observe and diagnose client needs ( } 8 \text { items) } \\
\text { absessment }\end{array}$ \\
$\begin{array}{l}\text { ability to plan accurate nursing actions (7 items) } \\
\text { ability to carry out nursing actions effectively and with flexibility; ability } \\
\text { to evaluate the nursing actions accurately and objectively (21 items) }\end{array}$ \\
$\begin{array}{l}\text { ability to analyse, judge and think critically (6 items) } \\
\text { Social participation } \\
\text { Ego strength }\end{array}$ & $\begin{array}{l}\text { participation and concern in social affairs (9 items) } \\
\text { confidence and assertiveness (6 items) }\end{array}$ \\
\hline
\end{tabular}

Content validity of the modified instrument was assessed by a panel of nurse academics and senior practitioners. The instrument was piloted with 12 graduates from a previous cohort. Minor modifications were made to question wording to improve understanding and one or two items were added. The same instrument was used to obtain mentors' perceptions of graduates' competencies, with slight modifications in the wording of instructions.

Reliability coefficients of the Hong Kong instrument ranged from .72 to .89 . The instrument modified for this study was tested for overall internal consistency between items, which produced an alpha coefficient of .95 . Each construct was then tested separately. The alphas produced all signify an acceptable level of internal consistency within instrument constructs (Table 2).

\section{Findings}

Responses were obtained from $63 \%$ of the graduates $(n=51), 68 \%$ of the diplomates $(n=28), 78 \%$ of the graduates' mentors $(n=40)$ and $77 \%$ of the diplomates' mentors $(n=17)$ (Table 3$)$.

Presentation of the results is organized to illustrate the following: multivariate comparisons between graduates

Table 2 Internal reliability of constructs used in the measurement of competence

\begin{tabular}{ll}
\hline Construct & Cronbach Alpha \\
\hline Leadership & 0.7797 \\
Professional development & 0.6923 \\
Assessment & 0.8352 \\
Planning & 0.7969 \\
Intervention & 0.8987 \\
Cognitive ability & 0.7410 \\
Social participation & 0.7972 \\
Ego strength & 0.6804 \\
\hline
\end{tabular}

and diplomates on each occasion (on graduation, 6 months and 1 year post graduation); longitudinal analysis of graduates' and diplomates' scores for each construct; multivariate comparison of mentors' scores between graduates and diplomates; agreement between students' and mentors' scores and a consideration of non-response.

\section{MULTIVARIATE COMPARISONS BETWEEN GRADUATES AND DIPLOMATES ON EACH OCCASION}

Analysis of variance was used to compare the mean scores of graduates and diplomates for all eight constructs simultaneously on each of the three occasions: on graduation, at 6 months and a year after graduation. Where a statistically significant difference was found between groups in the multivariate test, the individual constructs were compared to identify the most important determinants of that difference.

On graduation a significant difference was revealed in the mean scores of graduates and diplomates across the eight constructs (Wilks' lambda: $F=2.883$, d.f. $=8,68$, $P=0.008)$. Univariate tests on the constructs show statistically significant differences between graduates and diplomates in their mean scores for the leadership construct. $(P<0.001)$. Tables 4 and 5 show that diplomates had higher scores for leadership on graduation.

Six months after graduation, a significant difference was revealed in the mean scores of graduates and diplomates across the eight constructs (Wilks' lambda $F=2.862$, d.f. $=8,57, P=0.013$ ). Comparing means for individual constructs identified statistically significant differences between graduates and diplomates in their mean scores for three constructs: professional development $(P=0.0096)$, assessment $(P=0.008)$ and ego strength $(P=0.028)$. Tables 4 and 5 below shows that the graduates had higher mean scores than diplomates for each of these three constructs at 6 months. 
Table 3 Response rates

\begin{tabular}{|c|c|c|c|c|c|c|c|c|}
\hline & \multicolumn{4}{|c|}{ Students } & \multicolumn{4}{|c|}{ Mentors } \\
\hline & \multicolumn{2}{|c|}{ Graduates } & \multicolumn{2}{|c|}{ Diplomates } & \multicolumn{2}{|c|}{ Graduates } & \multicolumn{2}{|c|}{ Diplomates } \\
\hline & $\%$ & $n$ & $\%$ & $n$ & $\%$ & $n$ & $\%$ & $n$ \\
\hline On graduation & 63 & 51 & 68 & 28 & 78 & 40 & & 17 \\
\hline 6 months & 52 & 42 & 47 & 25 & $\mathrm{~N} / \mathrm{A}$ & $\mathrm{N} / \mathrm{A}$ & $\mathrm{N} / \mathrm{A}$ & $\mathrm{N} / \mathrm{A}$ \\
\hline 12 months & 47 & 38 & 51 & 21 & $\mathrm{~N} / \mathrm{A}$ & $\mathrm{N} / \mathrm{A}$ & $\mathrm{N} / \mathrm{A}$ & $\mathrm{N} / \mathrm{A}$ \\
\hline
\end{tabular}

One year after graduation, a significant difference was revealed in the mean scores of graduates and diplomates across the eight constructs (Wilks' lambda $F=2.862$, d.f. $=8,52, P=0.010$ ). Considering the individual constructs, univariate tests identify statistically significant differences between graduates and diplomates in their mean scores for the professional development construct $(P=0.046)$. Table 4 shows that graduates had the higher mean score for professional development at 12 months.

\section{LONGITUDINAL ANALYSES OF GRADUATES' AND DIPLOMATES' SCORES FOR EACH CONSTRUCT}

A repeated measures model was used to compare changes in mean scores for each construct during the year after graduation between graduates and diplomates. Each analysis provided a test of the main effects of the type of course (degree/diploma) and occasion (on graduation, 6 and 12 months post-graduation) and the interaction between these two factors. Tests for an interaction effect were able to assess whether mean scores for each construct of graduates and diplomates followed the same pattern of change over time (Table 5).

Table 5 shows that for professional development, assessment, planning and intervention, there was no statistically significant evidence of either differences in mean scores between graduates and diplomates or in mean scores during the year following completion of the course.

For social participation, cognitive ability and ego strength, there was statistically significant evidence of changes in mean scores during the year after graduation. However, there were no statistically significant differences between graduates and diplomates in either their mean scores or in the pattern of change over time.

For leadership, there were both differences between graduates and diplomates and also changes over time. Table 4 shows that diplomates had higher mean scores for leadership than the graduates although the difference appeared to reduce during the year following graduation. The statistical tests show that the differences between the two types of students are statistically significant, but as the interaction is not statistically significant, it cannot be concluded that (outside of the particular sample of students studied) the gap between graduates' and diplomates' mean scores for leadership changes over time.

\section{COMPARISON OF MENTORS' SCORES BETWEEN GRADUATES AND DIPLOMATES}

Here, analysis of variance was used again to simultaneously compare graduates' and diplomates' scores (as given by their mentors) for all eight constructs (Table 6). There was no statistically significant evidence that mean

Table 4 Mean scores of diplomates and graduates at graduation, 6 months and 12 months post-graduation

\begin{tabular}{|c|c|c|c|c|c|c|}
\hline \multirow[b]{2}{*}{ Construct } & \multicolumn{3}{|l|}{ Diplomates } & \multicolumn{3}{|l|}{ Graduates } \\
\hline & Graduation & 6 months & 12 months & Graduation & 6 months & 12 months \\
\hline Leadership & 3.03 & 2.95 & 3.27 & 2.71 & 2.89 & 3.18 \\
\hline Professional development & 3.27 & 3.11 & 3.09 & 3.26 & 3.33 & 3.29 \\
\hline Assessment & 3.32 & 3.10 & 3.31 & 3.34 & 3.37 & 3.45 \\
\hline Planning & 3.31 & 3.23 & 3.22 & 3.32 & 3.32 & 3.32 \\
\hline Intervention & 3.40 & 3.34 & 3.44 & 3.39 & 3.45 & 3.48 \\
\hline Cognitive ability & 3.28 & 3.01 & 3.22 & 3.31 & 3.12 & 3.24 \\
\hline Social participation & 2.57 & 2.28 & 2.59 & 2.44 & 2.41 & 2.49 \\
\hline Ego strength & 3.17 & 2.99 & 3.23 & 3.18 & 3.21 & 3.35 \\
\hline
\end{tabular}


Table 5 Results of the repeated measures analysis

\begin{tabular}{|c|c|c|c|c|}
\hline Construct & Effect & $\mathrm{F}$ & d.f. & $\mathrm{p}$ \\
\hline \multirow[t]{3}{*}{ Assessment } & Type (graduate/diplomate) & 3.10 & 1,56 & 0.084 \\
\hline & Time (graduation/ $+6 \mathrm{~m} /+12 \mathrm{~m})$ & 2.55 & 2112 & 0.082 \\
\hline & Type $\times$ Time & 1.86 & 2112 & 0.160 \\
\hline \multirow[t]{3}{*}{ Cognitive ability } & Type (graduate/diplomate) & 1.02 & 1,56 & 0.318 \\
\hline & Time (graduation/ $+6 \mathrm{~m} /+12 \mathrm{~m})$ & 6.80 & 2112 & $0.002 * *$ \\
\hline & Type $\times$ Time & 0.48 & 2112 & 0.623 \\
\hline \multirow[t]{3}{*}{ Ego strength } & Type (graduate/diplomate) & 1.26 & 1,55 & 0.267 \\
\hline & Time (graduation/ $+6 \mathrm{~m} /+12 \mathrm{~m})$ & 4.80 & 2110 & $0.010^{* *}$ \\
\hline & Type $\times$ Time & 0.71 & 2110 & 0.495 \\
\hline \multirow[t]{3}{*}{ Intervention } & Type (graduate/diplomate) & 0.78 & 1,56 & 0.382 \\
\hline & Time (graduation/ $+6 \mathrm{~m} /+12 \mathrm{~m})$ & 0.83 & 1,56 & 0.439 \\
\hline & Type $\times$ Time & 0.29 & 2112 & 0.751 \\
\hline \multirow[t]{3}{*}{ Leadership } & Type (graduate/diplomate) & 6.84 & 1,56 & $0.011^{*}$ \\
\hline & Time (graduation $/+6 \mathrm{~m} /+12 \mathrm{~m})$ & 15.58 & 2112 & $<0.001^{* * * *}$ \\
\hline & Type $\times$ Time & 2.26 & 2112 & 0.109 \\
\hline \multirow[t]{3}{*}{ Planning } & Type (graduate/diplomate) & 0.91 & 1,56 & 0.345 \\
\hline & Time (graduation $/+6 \mathrm{~m} /+12 \mathrm{~m})$ & 0.52 & 2112 & 0.593 \\
\hline & Type $\times$ Time & 0.38 & 2112 & 0.688 \\
\hline \multirow[t]{3}{*}{ Professional development } & Type (graduate/diplomate) & 3.71 & 1,56 & 0.059 \\
\hline & Time (graduation/ $+6 \mathrm{~m} /+12 \mathrm{~m})$ & 1.18 & 2112 & 0.310 \\
\hline & Type $\times$ Time & 2.60 & 2112 & 0.79 \\
\hline \multirow[t]{3}{*}{ Social participation } & Type (graduate/diplomate) & 0.19 & 1,55 & 0.664 \\
\hline & Time (graduation/ $+6 \mathrm{~m} /+12 \mathrm{~m})$ & 3.89 & 2110 & $0.023^{*}$ \\
\hline & Type $\times$ Time & 3.05 & 2110 & 0.052 \\
\hline
\end{tabular}

* $P<0.05$, ** $P<0.01$, **** $P<0.001$

Table 6 Mean scores of graduates and diplomates and their mentors/supervisors

\begin{tabular}{lllll}
\hline Construct & Diplomates & $\begin{array}{l}\text { Diplomates' } \\
\text { Supervisors }\end{array}$ & Graduates & $\begin{array}{l}\text { Graduates' } \\
\text { Mentors }\end{array}$ \\
\hline Leadership & 3.03 & 2.86 & 2.71 & 2.76 \\
Professional development & 3.27 & 3.32 & 3.26 & 3.23 \\
Assessment & 3.32 & 3.16 & 3.34 & 3.21 \\
Planning & 3.31 & 3.03 & 3.32 & 3.09 \\
Intervention & 3.40 & 3.26 & 3.39 & 3.26 \\
Cognitive ability & 3.28 & 3.11 & 3.31 & 3.15 \\
Social participation & 2.57 & 2.49 & 2.44 & 2.49 \\
Ego strength & 3.17 & 2.83 & 3.18 & 3.13 \\
\hline
\end{tabular}

scores of mentors differed between groups of students (Wilks' lambda: $F=1.570$, d.f. $=8,47, P=0.160$ ).

\section{AGREEMENT BETWEEN STUDENTS'} AND MENTORS' SCORES

For all students, the differences between students' own assessment and their mentor's assessment scores were calculated for each construct. Comparing these differences between graduates and diplomates, using analysis of variance, revealed no statistically significant differences between graduates and diplomates in agreement between mentors' and students' scores (Wilks' lambda: $F=1.239$, d.f. $=8,46, P=0.299$ ).

\section{NON-RESPONSE}

As the study progressed the numbers of students returning questionnaires decreased.

The numbers of questionnaires returned by students at each stage are indicated in Table 7.

Loss of respondents through attrition is common (Little \& Rubin, 1987), but is also of concern since longitudinal analyses may be based on groups of respondents which 
Table 7 Questionnaire response by graduates and diplomates

\begin{tabular}{llll}
\hline & On Graduation & After 6 months & After 12 months \\
\hline Graduates & 51 & 42 & 40 \\
Diplomates & 28 & 25 & 21 \\
\hline
\end{tabular}

may be increasingly biased if non-response is linked to the variables which are the subject of the analyses.

One way to evaluate the potential bias introduced by non-response is to see how the exclusion of cases who fail to respond affects conclusions based on analyses of data collected early in the study. Here data collected in the initial questionnaire were used to make comparisons between graduates and diplomates in their mean scores for the eight constructs. Re-analysis of these data incorporating a further factor, whether the student was still in the study by 1 year post graduation, showed that students' mean scores on graduation for the eight constructs did not differ significantly between responders and non-responders (Anova: Responder/Non-responder $\quad F=1.696, \quad$ d.f. $=8,194$, $P=0.101)$.

There is no statistically significant evidence that differences between graduates and diplomates in their scores at graduation depended on whether the student was a 'responder' or 'non-responder' at 1 year post graduation (Anova: Type $\times$ questionnaire returned after 1 years, $F=0.427$, d.f. $=8,194, P=0.904)$.

\section{Discussion}

The results suggest that on graduation there are no significant differences between degree and diploma graduates' competencies, except in leadership. In this area, diplomates' scores were higher than graduates. The longitudinal analysis did not show, however, that the differences between groups were maintained over time. Rather, a reduction in diplomates' leadership scores occurred. It is nevertheless of concern that qualifying degree graduates appeared to be less well prepared to lead and make decisions and the reasons for this need to be examined. Indeed it might be expected that the year longer course which the degree graduates undertook would provide more time to develop leadership skills, although the issue may be the content of the curriculum and not length of the course. It is possible that graduates sought and/or were presented with fewer opportunities than diplomates to exercise leadership during their clinical experience or in their first post. This could be associated with differing expectations of and support provided by employers in the two geographical areas, although this was not explored by the study.

The multivariate analysis at six months following graduation confirmed significant differences between the two groups in three areas of competence, namely professional development, assessment and ego strength. Graduates achieved higher scores than diplomates on all these constructs. Some of the attributes included within these constructs have been the subject of previous research comparing Project 2000 diplomates with conventionally trained qualifiers. For example, confidence (included in our measure of ego strength) was found by managers to be lacking in Project 2000 diplomates (Luker et al., 1996), as was their skills achievement and acquisition when they took up their first post. However, comparisons with graduates were not made. Conversely, Bircumshaw (1989b) reported that senior nurses viewed newly qualified graduate nurses as less confident than non-graduates, which was not supported by this study.

The low mean graduate leadership scores on graduation and the differences in professional development, assessment and ego strength could be due to lack of attention to these areas in the curriculum or because opportunities for nurses to gain such experience are restricted by geographical or financial constraints. These issues warrant further investigation. As the differences were particularly apparent on graduation, the importance of providing support and opportunities for graduates to develop their competence once in post is highlighted. Courses and preceptorships for newly qualified nurses are believed to be important for easing the transition into the qualified nurse role (Ahmadi et al., 1987; Pieri Flynn, 1997). Courses allow nurses a chance to consolidate their training and gain confidence, motivation and management skills through peer support, group discussions and time-out study days (Lathlean, 1987; Becker, 1990).

The findings from this study show signs that degree graduates make up ground quickly, a point illustrated by their higher score in assessment (ability to observe and diagnose client needs) at 6 months. Similar findings of improvement in the year following graduation have been noted in another British study conducted by Battersby \& Hemmings (1991). However, at 1 year the only difference found between groups was in relation to Professional Development, meaning that graduates participated more in continuing education and enhancement of professional standards than diplomates. This might suggest greater opportunity or desire for higher academic and professional attainment on the part of graduates and is consistent with findings from a national survey which found that a greater proportion of graduates had the opportunity to attend 
courses than other Project 2000 or conventionally qualified nurses (Luker et al., 1996). Again, it could have been local variations in availability of educational and professional development opportunities that accounted for these differences.

The limitations of the findings based on group comparisons at each point in time should be recognized. The longitudinal analysis only found evidence of change in mean scores for social participation, cognitive ability and ego strength over the year post graduation, and no statistical evidence of differences between group means over time was identified for any of the constructs. It is nevertheless reassuring that the scores of both groups generally increased in these areas of competence, suggesting that time is required post-qualification to develop or consolidate such competencies. Social participation (participation and concern in social affairs) was the lowest scoring construct of both groups and perhaps reflects the lower priority it receives, possibly in the curriculum and the profession generally.

\section{Methodological discussion}

While there are a number of limitations associated with using a self-completion instrument to measure competencies, the design of this study was strengthened by obtaining simultaneously the scores for graduates and diplomates provided by their mentors and supervisors. As these were not significantly different from those obtained directly from each group, the overall findings are generally supported. The consistency found in these competence scores suggests that graduates and diplomates have no false illusions of their abilities and this is always a good starting point from which to identify areas requiring improvement.

However, the debate continues over whether it is possible to measure nursing competence. The design of competence measures will inevitably be influenced by the purpose of the measurement. The rating scale used in this study allowed a comparison of nurses across different settings and geographical locations. However, measures may be developed for use in a particular clinical setting. In the AMICAE project (Benner, 1982), nurses were observed in their clinical environment and asked to provide a narrative of clinical events not purely on the process of events but also on their own interpretations and intentions. However, according to Girot (1993a), measurements that take regard of settings and individuality are subjective and are difficult to generalize from because they are context-specific.

There were no statistical differences between the mentor/supervisor and diplomate/graduate scores, possibly indicating either consensus or a limitation of the small sample sizes. However, it is recognized that the subjective/perceived vs. objective/observed debate is a common theme throughout the competence measurement literature both in relation to the choice of measurement tools and the individual conducting the measuring. Rating scales are criticized for being too specific, reductionist and alien to the practice setting and may be used by an individual (such as a mentor) influenced by the personality or background of the observed. Indeed, many mentors in reality have little opportunity for prolonged contact with their assigned nurses due to competing constraints of time, unit management, increased need for cost efficiency, and high patient throughput (Greenwood, 1993; Atkins \& Williams, 1995; Prowse, 1996). Hence the mentor/supervisor may have been asked to complete a questionnaire without having observed or having adequate professional contact with the newly qualified nurses.

In contrast, qualitative measures which explore nurse perceptions and interpretations, are criticized for being context specific and lacking standardization. As a result the multimethod approach has become popular, providing both qualitative and quantitative data and enabling comparisons between the results. The rating scale adapted for this study may benefit from further conceptual analysis with nurses themselves to explore the contemporary issues related to competence and to incorporate the concept of 'fitness for purpose'. A multi-method approach which first explores the concept of competence of nurses in relation to their 'fitness for purpose' may aid the development of a UK scale.

\section{Conclusion}

This small study attempted to compare the competence of diplomates and graduates from two different universities at three time points over the first post-qualifying year. In the absence of nationally agreed or defined standards for nursing competence, an instrument was developed to measure self-perceived levels of competencies by drawing on the existing measures, literature and exploratory work. The instrument was found to have reached acceptable levels of internal consistency. Despite problems with attrition of subjects over the course of the study, the findings highlight some potential areas of difference between graduates and diplomates on qualifying and at subsequent time points.

While the findings are not conclusive, it is possible that despite the similarities in competence of diplomates and graduates on qualifying, over time the graduates may overcome any initial limitations and indeed become more 
competent than the diplomates in certain areas. It can therefore be suggested from the study that there are possible advantages associated with the degree programme (Adult Nursing branch) over the diploma programme, although it is not possible to extrapolate the findings beyond the programmes included in this study. Other studies of competence have also found that graduates score more highly in certain competencies than diplomates after graduation (While et al., 1995a).

One of the limitations of this study is that there is no way of knowing how the qualifiers' self-perceptions of their competence were related to real life performance. While the scores suggest that on average both diplomates and graduates perceived that they were achieving the competencies listed all or most of the time, the results do not allow judgements to be made about what is an acceptable level of performance in practice. Furthermore, judgements by recipients of care, the patients, have not been taken into account in this study. Further research is recommended to address these issues, with larger samples drawn from programmes across the UK.

The main implications of this study are, firstly, for the curriculum. Greater attention to leadership and management may be required in the final year of the degree curriculum if qualifying graduates are to feel competent in this area. Additionally, more attention to social awareness and participation is necessary in both programmes and might be addressed through increasing the liberal studies component in the curriculum. Opportunities for this will inevitably be reduced, however, as the 4 -year degree is replaced by a 3-year programme. Secondly, there are implications for the level of support afforded to qualifying nurses in their first staff positions. The need for a preceptorship arrangement has been proposed by the United Kingdom Central Council for Nursing, Midwifery \& Health Visiting (1990, p.19) and could be an important means of assisting newly qualified staff to gain confidence. Thirdly, it will also be important for employers to support diplomates in their continuing education if they are to achieve the same level of competence as graduates in professional development during the first post-qualifying year.

\section{References}

Ahmadi K.S., Speedling E.J. \& Kuhn-Weissman G. (1987) The newly hired hospital nurse's professionalism, satisfaction and alienation. International fournal of Nursing Studies. 24(2), 107-121.

Atkins S. \& Williams A. (1995) Registered nurses' experiences of mentoring undergraduate nursing students. Fournal of Advanced Nursing. 21, 1006-1015.
Barlett H., Chan S., Wong F. \& Pang P. (1993) Measuring competence in BSN graduates. Department of Health Sciences, Hong Kong Polytechnic, Hong Kong.

Battersby D. \& Hemmings L. (1991) Clinical performance of University nursing graduates. Australian Fournal of Advanced Nursing 9(1), 30-34.

Becker R. (1990) Out of the frying pan... Nursing 4(22), 8-21.

Benner P. (1982) Issues in competency-based testing. Nursing Outlook. May, 303-309.

Benner P. (1984) From Novice to Expert: Excellence and Pomer in Clinical Nursing Practice. Addison Wesley, London.

Bircumshaw D. (1989a) How can we compare graduate and nongraduate nurses? A review of the literature. Fournal of Advanced Nursing 14, 438-443.

Bircumshaw D. (1989b) A survey of the attitudes of senior nurses towards graduate nurses. Fournal of Advanced Nursing 14, 68-72.

Chappel C. \& Hagar P. (1994) Values and competency standards. Journal of Further and Higher Education 18(3), 12-23.

Davis B.D. \& Burnard P. (1992) Academic levels in nursing. Fournal of Advanced Nursing 17, 1395-1400.

De Back V. \& Mentkowski M. (1986) Does the baccalaureate make a difference?: Differentiating nurse performance by education and experience. Fournal of Nursing Education 25(7), 275-285.

Fitzpatrick J.M., While A.E. \& Roberts J.D. (1993) The relationship between nursing and higher education. Fournal of Advanced Nursing 18, 1488-1497.

Girot E.A. (1993a) Assessment of competence in clinical practice - a review of the literature. Nurse Education Today 13, 83-90.

Girot E.A. (1993b) Assessment of competence in clinical practice: a phenomenological approach. Fournal of Advanced Nursing 18, 114-119.

Gray J.E., Murray L.S., Roy J.F. \& Sawyer J.R. (1977) Do graduates of technical and professional nursing programs differ in practice? Nursing Research 26(5), 368-373.

Greenwood J. (1993) The apparent desensitization of student nurses during their professional socialization: a cognitive perspective. Fournal of Advanced Nursing 18, 1471-1479.

Hover J. (1975) Diploma vs. degree nurses: are they alike? Nursing Outlook 23(11), 684-687.

Howell F.J. (1978) Employers' evaluations of new graduates. Nursing Outlook July, 448-451.

Lathlean J. (1987) Prepared Transition. Nursing Times 83(37), 42, 44, 47.

Little R.J.A. \& Rubin D.B. (1987) Statistical Analysis with Missing Data. Wiley, New York.

Luker K., Carlisle C., Riley E., Stilwell J., Wilson R. \& Davies C. (1996) Project 2000 Fitness for Purpose. Report to the Department of Health. Universities of Liverpool and Warwick.

McCloskey J.C. (1983) Nursing education and job effectiveness. Nursing Research 32(1), 53-58.

McCloskey J.C. \& McCain B. (1988) Nurse performance: Strengths and weaknesses. Nursing Research 37(5), 308-313.

McMillan S.C. (1985) A comparison of the professional performance examination scores of graduating associate and baccalaureate degree nursing students. Research in Nursing and Health $8(2), 167-172$.

Nelson L.F. (1978) Competence of nursing graduates in technical, communicative, and administrative skills. Nursing Research 27(2), 121-125. 
Pieri Flynn J., ed. (1997) The Role of the Preceptor: a Guide for Nurse Educators and Clinicians. Springer Publishing Company, New York.

Prowse M.A. (1996) Linking knowledge and practice through teacherled placements for students. Nursing standard 10(33), 44-48.

Ross M., Carroll G., Knight J., Chamberlain M., FothergillBourbonnais F. \& Linton J. (1988) Using the OSCE to measure clinical skills performance in nursing. Fournal of Advanced Nursing 13, 45-56.

Schwirian P.M. (1978) Evaluating the performance of nurses: a multidimensional approach. Nursing Research 27(6), 347-351.

The Concise Oxford English Dictionary. (1992) Laurence Urdang, ed. Oxford University Press, Oxford.

United Kingdom Central Council for Nursing Midwifery and Health Visiting (1990) The Report of the Post-Registration Education and Practice Project. UKCC, London.
Wandelt M.A. \& Stewart D.S. (1975) Slater Nursing Competencies Rating Scale, Appleton Century Crofts,. New York.

Waters V.H., Vivier M.L., Chater S.S., Urrea J.H. \& Wilson H.S. (1972) Technical and professional nursing: an exploratory study. Nursing Research 21(2), 124-131.

While A.E., (1994) Competence versus performance: which is more important? Fournals of Advanced Nursing 20, 525-531.

While A.E., Roberts J. \& Fitzpatrick J. (1995a) A Comparative Study of Outcomes of Pre-Registration Nurse Education Programmes. ENB; Department of Nursing Studies, Kings College, London.

While A.E., Roberts J. \& Fitzpatrick J. (1995b) A comparative study of outcomes of pre-registration nurse education programmes. ENB Research Highlights no. 10. 
INFORMATION POINT: Analysis of variance (ANOVA)

Further reading
Analysis of Variance is a method used to compare the means of several groups of observations. An F-test is used to test the null hypothesis that the means of all the groups of observations are equal. In its simplest form, ANOVA is called one-way analysis of variance. For example, we might measure the height of 10-year-old girls in five different countries and wish to test whether the mean height of 10-year-old females is the same in all five countries. If we only compared two countries we could use a $t$-test to carry out this investigation, so one-way analysis of variance can be considered as an extension of the $t$-test to cope with the situation in which we need to compare more than two groups simultaneously.

The analysis is based upon the assumption that the samples come from normally distributed populations with the same standard deviation. That is, we must be able to assume that the variable of interest is normally distributed within each group and that each group has the same standard deviation for that variable. If the assumption that the samples are from normal distributions is not viable, then the non-parametric test called the Kruskal Wallis test could be used instead, this is the non-parametric equivalent of one way ANOVA. Altman (1991) gives more detailed information about one way ANOVA and its non-parametric equivalent.

There are a number of ways in which analysis of variance might be further extended, but the assumptions of normality and equal standard deviation still need to hold. First, perhaps the observations could be grouped according to two different categorical variables (or factors, as they are often called). The extension allowing for two factors is called two-way ANOVA. For example, in our study of height of 10-year-old females one factor is country and another might be whether or not they were breast-fed.

A second extension of one way ANOVA is when we have two dependant variables that we wish to compare simultaneously across two or more groups. This extension is called multivariate analysis of variance (MANOVA). This has been used in the above paper to simultaneously consider the mean scores of the eight constructs (so the means of eight dependant variables) across two groups (the diplomats and the graduates). MANOVA is discussed in more detail with an example in Polit (1996).

Altman D.G. (1991) Practical Statistics for Medical Research. Chapman \& Hall. London. pp. 205-215.

Polit D.F. (1996) Data Analysis and Statistics for Nursing Research. Appleton and Lange, Stamford, Connecticut. pp. 317-324. 
INFORMATION POINT:

\section{Wilks' lambda}

Further reading
Wilks' lambda is a test statistic used in multivariate analysis of variance (MANOVA) to test whether there are differences between the means of identified groups of subjects on a combination of dependent variables. For example, in the paper above, the authors test whether the mean score of two groups, graduates and diplomates, is the same across eight constructs simultaneously. Thus, they are considering eight dependent variables and comparing the mean of this combination for two groups.

Wilks' lambda performs, in the multivariate setting, with a combination of dependent variables, the same role as the $F$-test performs in one-way analysis of variance. Wilks' lambda is a direct measure of the proportion of variance in the combination of dependent variables that is unaccounted for by the independent variable (the grouping variable or factor). If a large proportion of the variance is accounted for by the independent variable then it suggests that there is an effect from the grouping variable and that the groups (in this case the graduates and diplomates) have different mean values.

Wilks' lambda statistic can be transformed (mathematically adjusted) to a statistic which has approximately an $F$ distribution. This makes it easier to calculate the $P$-value. Often authors will present the $F$-value and degrees of freedom, as in the above paper, rather than giving the actual value of Wilks' lambda.

There are a number of alternative statistics that can be calculated to perform a similar task to that of Wilks' lambda, such as Pillai's trace criterion and Roy's gcr criterion; however, Wilks' lambda is the most widely used. Everitt \& Dunn (1991) and Polit (1996) provide more detail about the use and interpretation of Wilks' lambda.

Everitt B.S. \& Dunn G. (1991) Applied Multivariate Data Analysis. Edward Arnold. London. pp. 219-220.

Polit D.F. (1996) Data Analysis and Statistics for Nursing Research. Appleton and Lange, Stamford, Connecticut. pp. 320-321. 